\title{
Estratégias de produção e Mercado de uma organização produtora de cachaça: uma abordagem construtivista
}

\section{Cachaça production and Market strategy:} a realistic constructivist approach

\section{Christiane Batista de Paulo Lobato}

Universidade Federal de Lavras (UFLA)

email:christianelobato@unilavras.edu.br

\section{Mozar José de Brito}

Universidade Federal de Lavras (UFLA)

email:mozarbrito@gmail.com

\author{
Valéria da Glória Pereira Brito \\ Universidade Federal de Lavras (UFLA) \\ email:vgpbrito@gmail.com
}

\section{André Luiz de Paiva}

Programa de Pós-Graduação em Administração

Universidade Federal de Lavras (UFLA)

email:andrepaiva2@gmail.com

\section{RESUMO}

Este artigo tem como objetivo principal compreender a construção das práticas estratégicas de produção artesanal e inserção mercadológica de uma organização produtora de cachaça orgânica a partir dos fundamentos ontológicos da abordagem construtivista realista. Para tanto, empregou-se o método de estudo de caso. Esta escolha metodológica permitiu a aplicação do framework de análise que aborda a imbricação entre os contextos macro e micro social, a práxis, as práticas e os praticantes envolvidos na construção das estratégias de produção e mercado de uma pequena organização produtora de cachaça orgânica. Evidencia-se nos resultados a capacidade reflexiva dos praticantes em combinar saberes tradicionais e saberes técnico-científico e as práticas de mercado (representação, normativas e trocas). Por fim, o artigo ratifica a relevância da contextualização (micro e macrossocial) para os estudos da estratégia como prática social.

Palavras-Chave: Estratégia como prática; Construtivismo Realista; Cachaça; Minas Gerais; Práxis

\section{ABSTRACT}

This article has as main objective to understand the construction of the strategic practices of artisanal production and market insertion of an organization producing organic cachaça from the ontological foundations of the realist constructivist approach. For this, the case study method was used. This methodological choice allowed the application of the analysis framework that addresses the overlap between macro and micro social contexts, praxis, practices and practitioners involved in building the strategy of the production and market strategies of a small organization producing organic cachaça. The results show the reflective capacity of practitioners to combine traditional and technical-scientific knowledge and market practices (representation, rules and exchanges). Finally, the article ratifies the relevance of contextualization (micro and macrosocial) for studies of strategy as a social practice.

Key-words: Strategy as a practice; Realistic Constructivism; Cachaça; Minas Gerais; Praxis 


\section{INTRODUÇÃO}

A produção e a comercialização de cachaça de alambique atravessou centenas de anos e continua sendo realizada em diferentes espaços localizados em todo o território brasileiro. No contexto internacional, a bebida tem sido reconhecida como um produto oriundo da tradição cultural brasileira. Informações do Centro Brasileiro de Referência da Cachaça - IBRAC (2020) evidenciam que o arranjo produtivo brasileiro da cachaça conta com cerca de 40.000 organizações, sendo que $98 \%$ delas são micro e pequenas organizações. Elas preservam a tradição de produção de cachaça de modo artesanal, bem como geram renda e trabalho para milhares de pessoas. A cachaça é patrimônio histórico e cultural brasileiro e é o $3^{\circ}$ destilado mais consumido no mundo. Seu market share alcança $87 \%$ do mercado brasileiro de destilados (IBRAC, 2020).

Não obstante a relevância socioeconômica e histórica da cachaça, a gestão de sua produção e inserção de mercado tem sido muito pouco explorada por pesquisadores da área de administração. Em consulta à base Ibero-americana Scielo encontra-se 116 artigos científicos, sendo que somente 6 abordaram temas sobre gestão de organizações produtoras de cachaça. Este número ampliou-se para 15 artigos quando consultou-se a base Spell. Entre os artigos publicados em periódicos, 5 discutem aspectos estratégicos relacionados à produção e comércio da bebida (PAIVA, et al. 2018, VILLAR; WALTER, 2014, NEUTZLING; et al. 2015, RODRIGUES NETO; FREITAS, 2012, DOMINGOS; BAETA; BARBOSA, 2002). Portanto, há uma realidade organizacional que carece de pesquisas que compreendam especialmente as estratégias de produção e de inserção mercadológica de organizações produtoras de cachaça de alambique.

Neste artigo apresenta-se um estudo de caso que explora estes temas a partir da ontologia construtivista realista (FLECK, 2010) e da abordagem da estratégica como prática (WHITTINGTON, 2006). Desse modo, assume-se que a estratégia deve ser observada e apreendida como um produto da ação humana, não sendo, portanto, um ativo reificado das organizações. Mais precisamente, a estratégia passa a ser analisada tomando-se como categorias de análise a práxis, as práticas e os praticantes imersos em organizações situadas em contextos sócios históricos específicos (VAARA; WHITTINGTON, 2012).

Esse embasamento, direcionado às realidades organizacionais evidenciadas no mercado da cachaça de alambique, direcionam à seguinte questão de pesquisa: como as estratégias de produção de cachaça e de inserção mercadológica são construídas pelos praticantes em uma organização? A busca de resposta para essa questão levou ao desenvolvimento de um estudo de caso que teve por objetivo apreender a construção das estratégias de produção artesanal e inserção mercadológica de uma organização produtora de cachaça orgânica. Mais especificamente, pretendeu-se: a) retratar o contexto sócio histórico em que a organização estudada está inserida, particularizando o momento de sua criação e os elementos contextuais que marcaram a sua trajetória; b) interpretar a práxis que deu origem à construção das estratégias e suas eventuais modificações ao longo do tempo;c) mapear e descrever as práticas constitutivas das estratégias de produção e inserção mercadológica construídas, destacando os sentidos atribuídos pelos praticantes ao seu caráter performativo.

O artigo foi estruturado em 7 seções, sendo a primeira delas a introdução. Na segunda parte, apresenta-se a fundamentação teórica que deu origem a formulação de um framework de análise. Na terceira, esclarece-se o percurso metodológico trilhado na realização da pesquisa de campo. Na quarta, retrata-se a trajetória da organização e sua inserção no contexto sócio histórico. $\mathrm{Na}$ quinta e sexta partes, relata-se o estudo de caso realizado. $\mathrm{Na}$ sétima, descreve-se as considerações finais.

\section{ESTRATÉGIA COMO PRÁTICA: FUNDAMENTOS TEÓRICOS E CATEGORIAS DE ANÁLISE}

A abordagem estratégia como prática tem contribuído para o avanço do conhecimento sobre o modo como se concebe e pratica a pesquisa sobre estratégia (GOLSORKHI et al. 2015; VAARA; WHITTINGTON, 2012).Para estes autores, a pesquisa realizada fundamentada neste entendimento tem possibilitado que a estratégia seja estudada como produto da ação coletiva. Jarzabkowski, Balogun e 
Seidl (2007) conceberam a estratégia sob esta perspectiva como sendo um nexo ou fluxo de atividades socialmente construídas e realizadas por meio de ações, interações, negociações entre múltiplos atores. Portanto, tratam-se de práticas situadas no tempo e no espaço organizacional que produzem efeitos e implicações para a performance, a sobrevivência e o futuro das organizações. Contudo, esta abordagem não se limita à compreensão destes efeitos e implicações (WHITTINGTON, 2006), mas também abarca a compreensão da práxis, das práticas e dos praticantes.

A práxis é discutida por Whittington (2006) como sendo aquilo que os praticantes fazem, ela envolve as atividades necessárias à formulação e implantação da estratégia. Nesse sentido, a práxis é o trabalho realizado pelos praticantes para construir a estratégia (JARZABKOWSKI; BALOGUN; SEIDL, 2007). Para estes autores, esta definição precisa ser aprimorada e melhor explicada. Por isso, recorre-se à filosofia da práxis de Vazquez (2007), que conceitua a práxis como uma ação autônoma, criativa e transformadora por meio do qual as pessoas constroem e transformam a realidade e a si mesmo. Por sua vez, nesta perspectiva, a prática, enquanto um momento da práxis, envolve um conjunto de atividades de caráter utilitário-pragmático que visa atender as aspirações, interesses, objetivos mais imediatos de agentes ou pessoas pertencentes a um determinado espaço social. A práxis pressupõe também a integração reflexiva entre teoria e prática, indispensável para construir e transformar a realidade (VAZQUEZ, 2007). Portanto, podemos conceber a práxis constitutiva da estratégia como ação transformadora marcada pela junção entre teoria e prática. Nas organizações, podemos encontrar diferentes modalidades de práxis: a criadora, reiterativa, reflexiva e espontânea. A práxis criadora pressupõe uma estreita relação entre o planejamento (idealização) e a ação (realização). Esta noção nos parece relevante para o entendimento da construção e modificação das estratégias ao longo do tempo. Por sua vez, a práxis reiterativa pauta-se na reprodução ou repetição acrítica das práticas, pois ela caracteriza-se pela ruptura entre o pensar e o agir, entre a teoria e prática, entre a formulação e implantação da estratégia. Contudo, nesta práxis poderá haver transposição de modelos de ação, mas as ações criativas que transforma a realidade serão inibidas (VAZQUEZ, 2007). A práxis reflexiva, assim como as demais, pressupõe a tomada de consciência e a utilização da reflexividade. A construção da estratégia exige a construção de diálogos, problematização e intervenção no curso de ação. A práxis reflexiva produz, em certa medida, novos conhecimentos e mudanças nas práticas preexistentes, bem como contribui para a emergência de outras práxis. As práxis espontâneas requerem um certo grau de consciência reflexiva, sendo que sua limitação produz uma práxis espontânea que não possui caráter transformador. Por sua vez, a "práxis reflexiva", produz efeitos sobre as próprias práticas. Trata-se de uma condição necessária à transformação da realidade e da própria práxis (VAZQUEZ, 2007). Assim, a práxis fornece os princípios de organizar e de fazer, tornando-se fundamental para definição de objetivos, estruturas organizativas, práticas de produção e inserção em mercados, entre outros dispositivos de gestão (SHIRIVASTAVA, 1986).

Por seu turno, as práticas são desenhadas ou criadas pelos praticantes a partir de uma determinada práxis estratégica (WHITTINGTON, 2006). As práticas, enquanto elemento constitutivo da práxis, foram definidas por Vazquez (2007) como sendo um conjunto de atividades de caráter utilitário-pragmático que são realizadas de modo atender fins mais imediatos propostos por agentes ou praticantes. Elas envolvem "comportamentos rotineiros que interconecta as atividades corporais e mentais, equipamentos, instrumentos e objetos e suas instruções de uso, conhecimentos, emoções, know-how, experiências e conhecimentos" (RECKWITZ, 2002, p. 249). Para este autor, as práticas socialmente construídas e organizadas são marcadas por relações de haver, poder e saber que servem de referência para construção da realidade, difusão de sentidos, entre outros aspectos simbólicos. Com isso, as práticas estão intrinsecamente conectadas por meio de interações que permitem a realização coletiva de atividades cotidianas nas organizações (JARZABKOWSKI; BALOGUN; SEIDL, 2007; VAARA; WHITTINGTON, 2012).

A noção de praticante incorporada pela abordagem da estratégia como prática colocou em evidência a capacidade de reflexão e ação dos humanos (WHITTINGTON, 2006; JARZABKOWSKI; BALOGUN; SEIDL, 2007; GOLSORKHI et al. 2015). Esta evidenciação, oriunda de teorias da prática, revela 
que a construção da estratégia depende da capacidade reflexiva e transformadora dos praticantes que se encontram imersos em relações estruturais e de mercado. As relações estruturais dizem respeito aos mecanismos de produção econômica, política e simbólica que condicionam a construção da estratégia e ação dos praticantes. As relações de mercado que possibilitam as práticas de trocas ou de consumo material e simbólico. Portanto, a apreensão das estratégias requer a compreensão da visão de mundo e da ação dos praticantes que estabelecem diálogos, constroem consensos políticos, mobilizam recursos, bem como interpretam os contextos micro e macrossocial, levando-se em consideração seus repertórios interpretativos.

Este termo foi criado por Potter e Wetherell (1987) para apreender e explicar a relevância do uso da linguagem na constituição do sujeito e da realidade em que ele está inserido. Para estes autores, as coisas que tomamos como fato são discursiva e materialmente engendradas pelas práticas sociais. A noção de repertório formulada por Potter e colaboradores fundamenta-se em três princípios (SPINK; FREZZA, 2004): i) a performatividade da linguagem produz efeitos sobre a realidade, assim como qualquer outra ação concreta; ii) a construção que diz respeito à escolha e utilização dos recursos linguísticos (repertórios interpretativos) preexistentes esclarece os modos pelos quais as pessoas constroem e estruturam os seus discursos, tornando-os factuais para aqueles que fazem parte da audiência; e iii) a variabilidade como resultante da construção e performatividade possibilita que a realidade seja interpretada de modo diverso devido a existência de diversos repertórios. Portanto, repertórios diferentes dão origem a diferentes versões de uma mesma realidade.

Para Spink e Freza (2004), a produção de sentidos acerca da realidade requer que as pessoas mobilizem estes repertórios carregando elementos culturais próprios de um determinado espaço sócio histórico. Entre estes diversos elementos tem-se as ideologias, valores, crenças, normas, saberes, práticas, discursos e elementos simbólicos, que se complementam ou se sobrepõem, dando origem a diferentes visões de mundo. Estas reflexões serão relevantes para a interpretação das práxis e práticas constitutivas das estratégias situadas no tempo e no espaço (HYDLE,
2015). Neste artigo, a construção (realização e modificação) da estratégia será observada, levando-se em consideração os repertórios interpretativos.

\subsection{Estratégia como prática: Um olhar sob a ótica construtivista realista}

O framework de análise empregado no estudo de caso em foco abriga as categorias de análise formuladas por Whittington (2006) e outras reflexões que julgamos relevantes para a apreensão e explicação da construção da estratégia como prática sob a ótica da ontologia construtivista realista proposta por Fleck (2010). Esta ontologia fundamenta-se em diversos pressupostos, a saber: a) o conhecimento produzido sobre uma dada realidade será sempre incompleto, transitório e marcado pela falibilidade; b) a dicotomia entre sujeito e objeto do conhecimento, entre natureza e cultura deve ser negada; c) a realidade investigada existe independentemente do nosso conhecimento sobre ela; d) a realidade é constituída pela historicidade e materialidade; e) a construção do conhecimento depende de conhecimentos preexistentes e da imbricação entre explicação e compreensão; f) a linguagem em ação e a hermenêutica são elementos necessários da construção da realidade.

Muitos destes pressupostos são também reconhecidos por Grand, Rüeg-Sturm e Arx (2015) que defendem a aplicação desta ontologia no campo da estratégia como prática. Para estes autores, a pesquisa sob esta lente ontológica tem como foco a criação, construção, translação e transformação dos conceitos explicativos da estratégia e da sua concretização. Sob este prisma, a estratégia pode ser abordada como sendo socialmente construída. Ela seria um conjunto de práticas que sempre estão sendo construída e reconstruída a partir do pensamento criativo de praticantes e de outros atores envolvidos nesta dinâmica (GRAND; RÜEG-STURM; ARX, 2015). Com base na referida ontologia e na fundamentação teórica apresentada, formulou-se um framework teórico-metodológico (Figura 1) para estudar a construção de estratégias em uma organização produtora de cachaça orgânica. 


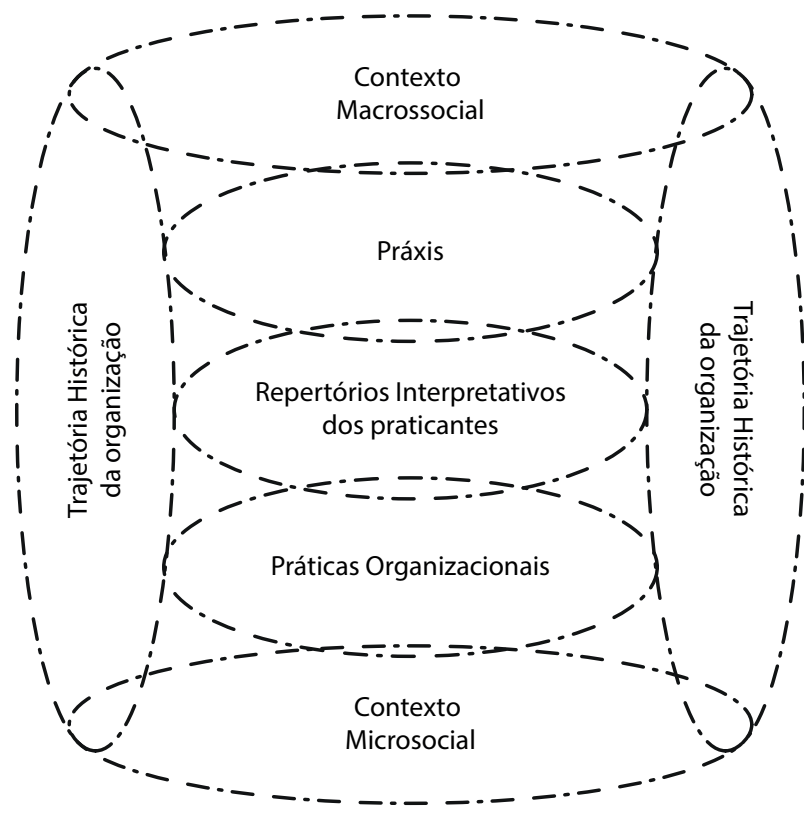

Figura 1 Representação gráfica da proposta teórico-metodológica.

Fonte: Elaborado pelos autores.

Trata-se de um framework que abriga os conceitos de repertórios interpretativos, práticas organizacionais, práxis social estratégica, trajetória organizacional e contextos micro e macrossocial (JARZABKOWSKI; BALOGUN; SEIDL 2007; VAARA; WHITTINGTON 2012; SEIDL; WHITTINGTON, 2014). Na sua elaboração, adotou-se uma postura reflexiva durante as escolhas teórico-metodológicas realizadas ao longo deste artigo. Por fim, esclarece-se que esta abordagem permite a investigação das interconexões entre a práxis, práticas e praticantes que integram reciprocamente a construção e reconstrução da estratégia. Destaca-se que a proposta também prevê a análise da trajetória da organização estudada e o seu contexto sócio histórico. As linhas traçadas evidenciam a interatividade entres categorias conceituais do framework e a trajetória da organização e seu contexto sócio histórico. Na próxima seção as escolhas metodológicas serão esclarecidas e justificadas.

\section{PROCEDIMENTOS METODOLÓGICOS}

A natureza do problema investigado, a adoção da ontologia construtivista realista por si mesmas justificariam a aplicação método de estudo de caso único de natureza qualitativa. Contudo, a seleção deste método nos permitiu a: i) exposição da história da organização e a contextualização do fenômeno estudado; ii) observação in loco das práxis e práticas constitutivas das estratégias em análise; iii) aplicação de diferentes procedimentos e técnicas de coleta e análise de dados; iv) descrição densa e mais apropriada das práxis e práticas a partir da recuperação da memória dos praticantes e de testemunhas chave; v) troca de experiências e vivências que foram fundamentais para a realização da pesquisa de campo; vi) aprendizagem de saberes tradicionais e saberes científicos que eram desconhecidos pelos pesquisadores que aplicaram o método de estudo de caso (EISENHARDT; GRAEBNER, 2007). Para estes autores, este método permite a apreensão, descrição densa e particular da realidade, especialmente quando se leva em consideração a trajetória histórica da organização e a descrição do contexto macrossocial em que as estas estão inseridas.

A organização escolhida emprega os sujeitos que fabricam a cachaça "Sonhador" (nome ficíticio). No processo de escolha desta unidade produtiva, levou-se em consideração a trajetória da organização e sua reputação. Ela foi pioneira na obtenção de certificação de produção de cachaça orgânica do Estado de MG. Além disso, observou-se o nexo de práticas que são realizadas para se produzir e comercializar a cachaça orgânica de modo artesanal. Finalmente, foi considerada a relevância do caso e da produção de cachaça de alambique, reconhecida pela Lei 16.688, de 11 de janeiro de 2007 como Patrimônio Histórico e Cultural de Minas Gerais, bem como o interesse dos praticantes em compartilhar seus conhecimentos e informações.

As concepções ontológicas adotadas e a escolha do método do estudo de caso orientaram a opção pela aplicação de diferentes técnicas de pesquisa qualitativa (CRESWELL; CLARK, 2007). Durante o trabalho de campo, optou-se pela realização de entrevistas em profundidade, observação direta e pesquisa documental (a partir de textos disponibilizados por meio da página eletrônica da organização estudada). As entrevistas em profundidade permitiram retomar a trajetória da organização, enfatizando-se os momentos de fundação e os aspectos contextuais que a marcaram. Para tanto, foi entrevistado o fundador que recontou a história da organização que ele e a fa- 
mília construíram. Posteriormente, foram realizadas mais 5 entrevistas em profundidade com membros da família e testemunhas-chave (1 técnico do Instituto Mineiro de Agropecuária (Ima), 1 Fiscal do Ministério da Agricultura, Pecuária e Abastecimento (Mapa) e 1 outro produtor de cachaça que conhece a organização). A realização destas entrevistas e da observação direta no campo foram determinantes para a descoberta e apreensão dos repertórios interpretativos dos praticantes acerca das práxis e práticas constitutivas das estratégias apreendidas por este estudo de caso. Por fim, ressalta-se a relevância da observação direta para o mapeamento e descrição das práticas de produção e de mercado. Para tanto, adotou-se uma postura indutiva própria da pesquisa qualitativa, observando as práticas a partir de um roteiro pré-definido, registrando durante a observação direta as informações julgadas como relevantes para a pesquisa.

Para o exame, interpretação e compreensão dos dados empregou-se a análise temática nos termos propostos por Braun e Clarke (2006). Iniciou-se este procedimento de análise pela familiarização dos temas associados às práticas. Nesta primeira etapa construiu-se uma visão de conjunto dos dados por meio do mapeamento inicial dos repertórios interpretativos construídos pelos praticantes em torno das práticas constitutiva das estratégias. No segundo momento, foram codificados os repertórios interpretativos e os temas a eles associados, levando-se em consideração as convergências e divergências entre eles. Esta codificação deu origem a uma matriz de repertórios interpretativos temáticos que abrigou as descrições dos temas e subtemas e excluiu os relatos de entrevistas e as notas do trabalho de campo considerados fora do eixo temático. No terceiro momento, realizou-se uma revisão desta matriz de repertórios interpretativos temáticos. Para tanto, revisou-se a homogeneidade e heterogeneidade, bem como as coerências e inconsistências dos repertórios interpretativos temáticos em relação aos objetivos e o framework estruturado. No quarto momento, foram agrupados os repertórios interpretativos temáticos levando em consideração a natureza das práticas constitutivas das estratégias em foco. Neste momento, efetivou-se uma aproximação analítica e reflexiva que possibilitou o diálogo entre a teoria e matriz de repertórios interpre- tativos temáticos. Esta análise integrativa permitiu a realização da descrição e análise da práxis e das práticas constitutivas das estratégias demarcadas. Para evitar um lapso temporal as análises foram realizadas imediatamente após a coleta de dados.

\section{ASPECTOS HISTÓRICOS: TRAJETÓRIA, PRATICANTES E ELEMENTOS CONTEXTUAIS}

A compreensão da estratégia de produção de cachaça orgânica e inserção mercadológica como prática impôs o desafio de recontar alguns aspectos da história da organização produtora de cachaça, particularizando a visão de negócio dos praticantes (princípios, valores e crenças) e alguns elementos sócio históricos que marcaram a trajetória da organização. A história da organização se confunde com a história do seu fundador, aqui denominado como Sr. Ariano. Será recontada a história de uma organização que utiliza somente a força de trabalho da família constituída por 4 pessoas. Sr. Ariano, líder da família proprietária da marca "Sonhador" é um senhor de pouco mais de 60 anos, com uma personalidade criativa e carismática, marcada por uma práxis ambientalista e praticante da agroecologia. Conforme relata, Sr. Ariano intitula-se como: "Cachaceiro (quem faz uso desmoderado de bebida alcoólica, principalmente a cachaça), Cachacista (quem produz a cachaça), Cachaçólogo (estudioso da cachaça) e cachacier (aquele que faz as misturas e diz que entende de cachaça)" (Relato de Entrevista).

Sr. Ariano herdou do bisavô o oficio e os saberes seminais necessários à produção de cachaça orgânica. Assim, após a morte deste patriarca os herdeiros deram prosseguimento à produção de cana de açúcar, rapadura e cachaça. Esta atividade era a base de sustentação da família. Portanto, fator decisivo para a consolidação do seu projeto, pois a variedade de cana de açúcar já estava adaptada ao solo e clima da região de Centro Oeste de Minas Gerais. A fração de terra em que a família trabalha foi herdada do pai, que também herdou parte da fazenda do bisavô de Sr. Ariano. Este fundador possui formação na área de geologia e metalurgia. A educação, segundo este líder, foi crucial para a sua trajetória profissional na empre- 
sa metalúrgica em que trabalhou. Ele permaneceu neste trabalho até o final da década de 1980, quando começou a refletir sobre a possibilidade de "mudar de vida". Além disso, realizou diversos treinamentos na área administrativa e aprendeu a lidar com as pessoas.

Após 15 anos de trabalho, negociou com a empresa a sua saída e partiu de modo definitivo para a estruturação de seu sitio e de seu alambique. Nas palavras, do entrevistado: "eu estava saindo da empresa e indo para um caminho de sucesso!" Contudo, antes de dar início ao empreendimento, este empreendedor realizou pesquisas e estudou o processo produtivo da cachaça. Embora tivesse algumas noções básicas, este praticante resolveu também trocar ideias e experiências com outros produtores de cachaça.

A fundação da organização se deu em um momento histórico singular, pois na década de 1980 emergia um significativo movimento político em defesa da produção da cachaça realizada no referido Estado (Silva, 2009). Inicialmente, este movimento foi liderado por uma equipe do Instituto de Desenvolvimento Industrial de Minas Gerais (INDI), que reconheceu em seus estudos a relevância social e econômica da produção de cachaça para a economia agrícola mineira. Este reconhecimento e as inciativas de lideranças do setor contribuíram para a criação em 1989, da Associação Mineira dos Produtores de Cachaça de Qualidade (AMPAQ), organização que tem contribuído com a construção do ambiente institucional que favorece a produção artesanal de cachaça de qualidade em Minas Gerais (Souza, 2004).

Além disso, o Estado atuou diretamente na institucionalização de um marco legal regulador das ações de diversos agentes participantes do arranjo produtivo da cachaça. Este processo contou com a participação de diversos agentes, incluindo o poder público, AMPAQ, órgãos de extensão, especialistas, entre outros. Neste arcabouço legal está inserido o Sistema de Certificação da Cachaça de Minas criado por meio do Decreto 42.644 de 5 de junho de 2002, que regulamentou a Lei ${ }^{\circ} 13.949$, de 11 de julho de 2001. Este ato normativo estabeleceu o padrão de identidade, definiu as especificidades do processo de fabricação da Cachaça de Alambique e os mecanismos de controle de qualidade e de sua certificação. Além disso, desde 2001, vem sendo construída de modo participativo, uma agenda estratégica para o arranjo produtivo da cachaça que valorizou a tradição de produção artesanal de cachaça e imprimiu uma profissionalização das organizações que se ajustaram a esta agenda. Este instrumento contribuiu para a consolidação da qualidade e da reputação da cachaça artesanal. Contudo, muitos problemas estruturais e históricos persistem, a exemplo, da produção e venda no mercado informal de cachaça fora das boas práticas de fabricação estabelecidas; a ausência de uma política de fomento destinado a pequenas unidades de produção; elevada carga tributária que afeta os custos de produção, a necessidade de intensificação da fiscalização da produção e da distribuição da cachaça no mercado.

É neste cenário, que a família liderada pelo fundador da organização em foco, optou pela estratégia de produção de cachaça orgânica como uma prática de diferenciação de outras cachaças fabricadas em Minas Gerais. Esta estratégia será explorada na próxima seção.

\section{A ESTRATÉGIA DA PRODUÇÃO ORGÂNICA, FAMILIAR E SUSTENTÁVEL}

A análise dos repertórios interpretativos dos praticantes entrevistados e das testemunha-chaves permitiram a apreensão das práxis e práticas constitutivas da estratégia de produção artesanal de cachaça orgânica. Entre as práticas constitutivas desta estratégia de produção da cachaça destaca-se o cultivo orgânico de cana de açúcar, a fabricação e a certificação.

\subsection{A prática do cultivo orgânico da cana de açúcar}

Ao se apropriarem de significados que se aproximam de uma ordem do discurso ambientalista, os praticantes, desde a década de 1980, cultivam da cana de açúcar sem o uso de substâncias que coloquem em risco a saúde humana e o meio ambiente. A realização desta prática envolve um ciclo de cultivo (do plantio a colheita) de cerca de 18 meses. Nesta prática de cultivo orgânico não são utilizados fertilizantes sintéticos solúveis, agrotóxicos e variedade de canas transgê- 
nicas. A colheita e limpeza da cana é manual. Para justificar esta escolha, os praticantes utilizam diversos argumentos que reproduzem alguns elementos de sua práxis. Para eles, este modo de produção tem um apelo ecológico muito valorizado pelo consumidor de cachaça, especialmente jovens e outros consumidores que procuram fazer uso consciente da bebida. A análise dos repertórios interpretativos também revela algumas crenças cultuadas pelos praticantes. Eles acreditam que a produção orgânica de cachaça: i) preserva a sua própria saúde e dos consumidores de cachaça orgânica; ii) reduz a poluição da água e a contaminação do solo e conserva a biodiversidade presente no cerrado mineiro; iii) contribui para a melhoria da renda e da qualidade de vida da família; iv) preserva a memória relativa às tradições e saberes do mundo rural; v) garante a sustentabilidade da organização em termos ambientais, econômicos, sociais; vi) fortalece a imagem da marca "Sonhador". Estas justificativas expressam a visão organizacional compartilhada pelos praticantes. Este ethos, além de servir de ponto de partida para a construção das estratégias em foco, marca as experiências e o convívio dos membros da família que trabalha unida e procura manter uma relação de harmonia entre a organização e o meio ambiente. Esta prática do cultivo orgânico não ocorre de modo isolado no tempo e no espaço. Ela exige agenciamentos que atendam aos interesses da organização, do mercado consumidor e do próprio Estado. As práticas constitutivas da estratégia de produção artesanal de cachaça orgânica dependem da qualidade da cana e do seu teor de sacarose. Esta interconexão entre práticas será evidenciada ao longo desta discussão dos resultados.

\subsection{A prática de fabricação da cachaça orgânica: 0 modo de produção Artesanal}

Esta prática é constituída por um nexo de atividades cuja origem está atrelada ao modo de produção artesanal praticado no período colonial. Portanto, optamos por abordá-la como um produto cultural, uma práxis consciente que articula dialogicamente saberes, práticas e atividades. O modo de produção artesanal enquanto práxis não se resume ao simples processamento e transformação da cana de açúcar em um produto destilado. Ao contrário, neste modo de produção recursos são mobilizados, bem como relações de haver e saber são construídas (Vazquez, 2007). Este modo de produção artesanal envolve a imbricação reflexiva entre teoria e prática. Estas práticas estão vinculadas às tradições próprias do período colonial que foram, ao longo do tempo, reproduzidas, reinterpretadas e institucionalizadas, de tal modo, que a cachaça tornou-se um produto cultural constitutivo do imaginário brasileiro (Silva, 2009).

No caso estudado, os praticantes herdaram saberes de seus antepassados e incorporaram também conhecimentos e práticas gerados pela pesquisa técnica-científica, incluindo aqueles relacionados ao controle de qualidade da produção. A herança, além de conter e perpetuar as experiências de outras gerações, valoriza a dimensão simbólica e mantém a tradição da produção artesanal. Diferente da cachaça industrializada, esta prática de produção artesanal, na organização pesquisada, é marcada pelo emprego intensivo da força de trabalho familiar, baixa escala de produção, escassez de fragmentação e automação do trabalho, adoção de técnicas de cultivo orgânico, controle rigoroso da qualidade e da higienização das atividades de extração, fermentação e destilação da cachaça em alambique de cobre. A produção artesanal, como parte de uma tradição, permite que os praticantes estabeleçam o elo entre o seu passado, presente e futuro.

Esta prática foi configurada por um nexo de atividades integradas que se inicia com a higienização e a extração do caldo da cana de açúcar. Esta atividade é realizada rigorosamente em até 24 horas após o corte da cana. Este rigor evita a perda do teor do caldo extraído da cana. A atividade de extração incorpora a ação humana, o uso de uma moenda elétrica e aplicação de conhecimentos de biossegurança que evitam a contaminação por microrganismos nocivos, bem como garante a qualidade do caldo. Uma vez extraído, o caldo passa pela decantação e filtragem para a retirada de microfibras de cana e outras impurezas e pelo ajuste do teor de açúcar (entre 14 e 16 Graus Brix) por meio da adição de água.

Logo após esta atividade, o caldo é canalizado para a fermentação que ocorre em dornas de aço inoxidável equipadas com dispositivos de controle da temperatura ideal para que leveduras encontradas 
naturalmente na cana de açúcar cultivada no local deem início ao agenciamento biológico que dura 24 horas. O uso deste tipo de levedura recorre aos repertórios interpretativos dos praticantes como forma de preservação da tradição da produção artesanal e valorização da identidade territorial da cachaça. Os praticantes monitoram permanentemente, esta atividade de fermentação, evitando a elevação de temperaturas e do índice de acidez do mosto (caldo de cana). Este controle evita a proliferação de bactérias nocivas que prejudicam a fermentação e a qualidade do produto final. Os saberes tradicionais, o conhecimento científico e experiências dos praticantes são decisivos, pois eles são referência na execução e avaliação da qualidade dos resultados desta atividade. Neste processo, os praticantes avaliam que são capazes de identificar a contaminação da fermentação, a partir da observação da ocorrência ou não de espuma, da presença de forte odor de vinagre, formação de aglomerados gelatinosos, aumento da viscosidade do caldo e da mediação do índice de acidez. Neste momento, como afirma o praticante: "todo cuidado é pouco". Como resultado da atividade de fermentação. tem-se o vinho que é, imediatamente, transferido por meio de tubos inox para o destilador feito de cobre. Qualquer atraso na transferência do caldo poderá também afetar a qualidade do vinho e a qualidade da destilação.

A prática de destilação recorre ao repertório dos praticantes como uma atividade complexa, que exige paciência e o domínio da técnica centenária de destilação. No caso específico, o alambiqueiro praticante domina profundamente esta técnica que envolve agenciamentos ou reações físico-químicas que são controladas e registradas pelos praticantes. A observação evidenciou também que esta atividade é realizada por parcelas ou de modo intermitente. Tanto a temperatura (entre 80 e $90^{\circ}$ ) quanto o ritmo da destilação (duração entre 1,5 a 3 horas) são controlados, de modo a evitar o aquecimento excessivo e manter ritmo do fluxo de destilação. Os praticantes também realizam, durante a destilação, o controle de qualidade da cachaça. Para tanto, eles separam a cachaça de cabeça (até $10 \%$ da quantidade inicial destilada), de cauda (até $10 \%$ da quantidade final) da cachaça do coração (no mínimo de $80 \%$ da quantidade total destilado). A análise dos repertórios interpretativos e das conversações realizadas durante a pesquisa evidenciou que esta atividade é carregada de sentidos. Para os praticantes, esta separação evita a contaminação da cachaça com componentes nocivos à saúde humana, preserva o paladar, o aroma e qualidade da cachaça. Além disso, a atividade de destilação é marcada por crenças e saberes tradicionais. Os praticantes acreditam que o uso do destilador ou alambique de cobre aquecido pela energia oriunda do bagaço de cana preserva a tradição da produção artesanal de cachaça e a qualidade da cachaça e evita a ressaca do consumidor. Para os praticantes a realização destas atividades também é sinônimo de adequação à legislação brasileira que define a identidade e os padrões de conformidade que a cachaça artesanal deve atender.

Uma vez destilada, a cachaça orgânica produzida de modo artesanal é armazenada e envelhecida. Estas atividades também incorporam saberes, trabalho humano, bem como a escolha de tonéis e barris de madeira. No caso estudado, os praticantes optaram por barris de madeira extraída de Carvalho Suíço cujas propriedades físico-químicas conferem à cachaça um padrão de qualidade sensorial superior e a diferencia em termos de cor, aroma e sabor. Além disso, o envelhecimento é uma atividade marcada pelo tempo e espaço. A cachaça envelhecida em barris de carvalho tem a sua tonalidade modificada em cerca de 30 dias e no prazo de 2 anos adquire odor típico da madeira. O sabor da cachaça também é alterado lentamente, tornando-se harmonioso e arredondado ao final de 3 anos. Quando ingerida, a cachaça envelhecida não provoca queimação. $\mathrm{Na}$ organização estudada, a cachaça é comercializada após 3 anos, quando ela alcança a qualidade e atende aos padrões de conformidade estabelecidos em lei e os interesses do mercado.

\section{A PRÁTICA DE CERTIFICAÇÃO E A ESTRATÉGIA DE INSERÇÃO MERCADOLÓGICA}

A compreensão da estratégia de inserção mercadológica praticada na organização pesquisada passa necessariamente pela apreensão da prática da certificação que será abordada no próximo item desta seção. 


\subsection{Certificação como prática de acesso ao mercado}

A certificação pode ser compreendida como uma prática avaliativa da conformidade e qualidade da cachaça (Soratto et al., 2007). Para estes autores, a certificação é realizada por organizações credenciadas pelo INMETRO - Instituto nacional de Metrologia, Qualidade e Tecnologia. Em Minas Gerais, o Instituto Mineiro de Agropecuária (IMA) é o órgão público credenciado para a realização da certificação da cachaça, entre outros produtos agropecuários.

Ao tomar conhecimento do programa Certifica Minas, em meados de 2004, Sr. Ariano procurou o IMA para se informar sobre o processo de certificação. Uma vez decididos pela implementação, a certificação da cachaça induziu a introdução de diversas modificações nas práticas constitutivas da estratégia de produção. Entre estas destacam-se a preparação da documentação necessária, a adequação da infraestrutura produtiva aos requisitos de conformidade, contratação dos serviços de certificação junto ao IMA, adequação de equipamentos, introdução de novas práticas de higienização e de segurança alimentar, qualificação dos demais membros da família, realização anual de análises de solo, água, caldo da cana e monitoramento permanente do processo de produção.

A certificação enquanto prática encontrou alguns obstáculos burocráticos que foram superados pelos praticantes. Contudo, a certificação recorre no repertório interpretativo dos praticantes como uma conquista, uma forma de reconhecimento do mérito do trabalho duro realizado em família. "A questão de certificação não foi problemática. Tivemos alguns entraves burocráticos, mas nada que não pudéssemos resolver". (Relato de Entrevista - Praticante) Além da burocracia, os praticantes enfrentaram o despreparo, à época, dos órgãos públicos em desenvolver o processo de certificação de produtos orgânicos. Para resolver muitos entraves relativos a qualquer processo de certificação foi realizada uma parceria junto ao MAPA. Este trabalho também contribuiu para a aprendizagem dos praticantes e técnicos dos órgãos públicos. Com isso, assim que esta fase de ajustes, formalizações e produção de memoriais de processos foi realizada, a obtenção do certificado junto ao IMA foi alcançada, em 2005.

A prática de certificação da produção da cachaça orgânica é interpretada pelos praticantes como uma espécie de passaporte para o mercado. Contudo, a análise dos repertórios interpretativos revela que seus fundamentos são também decodificados e interpretados pelos praticantes como um instrumento de controle, monitoramento, fiscalização e de vigilância. "Aqui trabalhamos conforme as exigências legais e as normas de qualidade. Temos que demonstrar que nossa produção de cana usa somente adubo orgânico que é produzido por nós. Tudo é avaliado, verificado e controlado" (Relato de Entrevista - Fundador). A certificação como sinônimo de controle e, portanto, poder, também é decifrada pelos praticantes como uma prática que melhorou a gestão, agregou novos conhecimentos que contribuíram para a melhoria contínua da prática de fabricação e da qualidade da cachaça orgânica.

A análise dos repertórios interpretativos evidenciou outros sentidos que são atribuídos à certificação que revela a dimensão simbólica que marca esta prática. Para os praticantes, a certificação simboliza para o mercado a seriedade do processo de produção da cachaça orgânica. Eles acreditam que os consumidores passam a entender que uma cachaça produzida deste modo preserva a sua saúde e o meio ambiente, bem como agrega valor à marca "Sonhador", facilitando a sua inserção em novos mercados.

Cabe ressaltar que a adesão das organizações à certificação é voluntária. Contudo, esta prática é permeada por relações de poder exercidas entre os agentes inseridos nesta estrutura. Deste modo, a certificação estabelece as regras do jogo e punições para aqueles que não cumprirem aquilo que foi pactuado e definido em Lei. O cumprimento das regras do jogo é verificado anualmente pela certificadora (IMA), que possui a prerrogativa de suspender de modo provisório ou definitivo a certificação daquelas organizações e das marcas que não atenderem aos requisitos de conformidade e qualidade da cachaça. Neste jogo estão envolvidos também os consumidores, que desejam consumir com segurança e de modo consciente a cachaça. Este consumo é decifrado pelos praticantes como uma forma encontrada pelo consumidor para valorizar uma tradição rural e a produção orgânica 
familiar. Esta inserção mercadológica será descrita no próximos item.

\subsection{A prática de inserção mercadológica}

Incialmente a inserção mercadológica realizada pelos praticantes foi via mercado informal. Ressalta-se que o mercado de cachaça é regido pelos princípios da concorrência regulada, legitimação das relações de trocas e dos interesses econômicos e reconhecimento do papel dos consumidores. Contudo, boa parte da produção de modo artesanal é distribuída no mercado informal, marcado pela concorrência predatória, distribuição de produtos de baixa qualidade (que colocam em risco a saúde de milhares de consumidores brasileiros considerados de baixa renda), evasão fiscal e pouca preocupação com a lógica da produção sustentável (Silva, 2009).

A organização estudada atuou neste mercado até o momento de sua formalização e certificação obtida, em 2005. A partir destes episódios estratégicos, os praticantes abandonaram gradativamente comercialização em pequenos varejos, bares e no próprio local de fabricação e passaram a realizar a distribuição de seus produtos em outros canais como supermercados, distribuidores e consumidores nacionais. A inserção mercadológica, narrada pelo fundador foi tomada neste artigo como conjunto de práticas de mercado socialmente construídas. Para explicá-la, foram utilizadas algumas categorias de análise formuladas por Kjellberg e Helgesson (2007) que definem um mercado como sendo um produto social constituído de práticas (atividades constitutivas e estruturantes do mercado) desenvolvidas ou realizadas pelos agentes que nele atuam. Para estes autores, os mercados são construídos a partir de práticas representacionais, normativas e de troca.

As práticas representacionais, enquanto produto do imaginário, incorpora imagens e outros elementos simbólicos que constituem o mercado de uma marca ou produto (Kjellberg \& Helgesson, 2007). A construção destas práticas foi determinante para consolidar a inserção da Cachaça "Sonhador" no mercado nacional e internacional. Para romper com imagem negativa comum à produção informal, os praticantes procuraram, além de promover certificação deste produto, construir uma representação social que con- feriu a marca visibilidade e reputação. Os praticantes, a todo momento, demonstram a diferenciação da cachaça por meio da vinculação da marca "Sonhador" à tradição da produção artesanal de uma cachaça orgânica que atende aos padrões de qualidade e não prejudica a saúde do consumidor. Além disso, listam as premiações recebidas pela marca e as certificações de conformidade e qualidade obtidas. Os principais meios de veiculação desta representação são: o site, a concessão de entrevistas a jornais e redes de TV e a participação em feiras de produtos orgânicos. Em síntese, os praticantes realizam práticas de comunicação em que evidenciam que o consumo de cachaça deixou de ser mero ato de beber e passou a simbolizar a qualidade, sofisticação, singularidade de cachaça orgânica e o respeito ao marco jurídico legal.

A inserção mercadológica da organização pesquisada se fundamenta em um conjunto de normas e regras que foram conceituadas por Kjellberg e Helgesson (2007) como práticas normativas. Estas práticas revelam as diretrizes, normas de conduta, regulamentações, formais e informais que regulam as trocas de mercado, as interações e transações entre os agentes que participam do mercado da cachaça. $\mathrm{O}$ Estado de Minas Gerais, de modo pioneiro, instituiu o programa mineiro de certificação da cachaça, estabeleceu normas de fabricação e mecanismos de controle de qualidade. Esta prática normativa disciplinou a inserção mercadológica, possibilitando que a organização pesquisada fizesse parte de um seleto grupo de organizações certificadas, que diferenciam os seus produtos, adotam novas tecnologias de produção orgânica e gozam de elevada reputação no mercado de produtos orgânicos. Hoje tanto a organização quanto a marca são reconhecidas e obtém resultados financeiros significativos, especialmente quando se leva em consideração o porte da negócio.

Por fim, as práticas de trocas definidas por Kjellberg e Helgesson (2007) como um conjunto de atividades concretas por meio das quais as trocas econômicas e simbólicas são realizadas entre as organizações e os consumidores (pessoas e organizações). Entre as práticas realizadas pela organização, destacaram-se a distribuição de seus produtos em redes de supermercados, a comercialização por meio eletrônico, a participação em feiras de produtos orgânicos, bem como feiras de agricultores familiares. A partir 
de 2007, a organização passou a comercializar o seu produto por meio do 'Portal B2B Trade' vinculado a área de negócios internacionais do Banco do Brasil. A exportação representa cerca de $30 \%$ da quantidade cachaça. Assim, os praticantes passaram a realizar, pioneiramente, exportações para diferentes países via correio e a circular em eventos e feiras internacionais de produtos orgânicos.

A prática do comércio eletrônico permitiu a exportação de maiores quantidade de cachaça orgânica para Itália, Argentina e México. Além disso, a organização atende consumidores finais em outros países, Estados Unidos, Alemanha e França. Os praticantes relataram que a recorrência de compras por parte de consumidores estrangeiros simboliza o reconhecimento da qualidade e do simbolismo de produtos sustentável que a marca materializa. A inserção internacional recorre nos repertórios interpretativos como uma atividade que garante a sustentabilidade econômica e financeira de uma micro organização e a sobrevivência da família de praticantes.

\section{CONSIDERAÇÕES FINAIS}

Neste artigo foi relatado um estudo que teve por objetivo apreender a construção das estratégias de produção artesanal e de inserção mercadológica de uma organização produtora de cachaça orgânica. Para tanto, foram adotados pressupostos ontológicos da abordagem construtivista realista, recorrendo aos fundamentos teóricos e ao método do estudo de caso que permitiram a retomada da trajetória histórica da organização e de sua inserção no contexto sócio histórico. Portanto, foi aplicado um framework de análise que permitiu a compreensão da estratégia de produção e mercado como prática sob uma construção sócio histórica constituída por práxis, práticas e repertórios interpretativos.

A análise dos repertórios interpretativos evidenciou que os princípios da produção agroecológica quando associados à consciência ambiental e a cultura da qualidade vivenciada pelos praticantes produziu uma práxis significativa para a construção das estratégias de produção e inserção mercadológica como prática na organização estudada. Esta práxis incorpora simultaneamente saberes tradicionais apreendidos na pratica cotidiana e conhecimentos técnico-científicos necessários à construção (realização e modificação) de estratégias organizacionais no espaço e no tempo. Assim sendo, pode-se constatar que a construção das estratégias é marcada por práxis transformativas que abrigam diferentes repertórios interpretativos. Estes repertórios são mobilizados pelos praticantes para produzirem sentido e reorientarem as práticas cotidianas constitutivas das estratégias de produção e mercado. Além disso, esta práxis foi crucial para construção de uma visão ou ethos organizacional que simboliza e materializa o respeito a saúde dos consumidores, a preservação do meio ambiente e a valorização do modo de produção artesanal e a qualidade. A materialização deste ethos organizacional, povoado por pressupostos, valores, crença, saberes, implica na reconstrução e reprodução de práticas constituídas por diversas atividades de caráter utilitário-pragmático, rotineiro, recursivo e reiterativo, a exemplo daquelas que constituem as práticas de produção e de mercado. Além de interconectar estas atividades, a realização das práticas exigiram, ao longo da trajetória histórica da organização, a mobilização de energia humana, agenciamentos biológicos e físico-químicos, equipamentos, instrumentos, objetos know-how, experiências e emprego conjugado de saberes tradicionais e científicos.

Acredita-se que o artigo é relevante para compreensão da estratégia como prática, especialmente no que refere à aplicação da ontologia construtivista realista e do framework teórico elaborado em outras realidades organizacionais. Além do mais, agrega-se um novo conceito de práxis e de repertórios interpretativos que se mostraram consistentes e úteis para explicar a emergência, construção e reconstrução de estratégias. Evidencia-se a capacidade reflexiva dos praticantes em combinar saberes tradicionais e saberes técnico-científico e as práticas de mercado (representação, normativas e trocas). Por fim, o artigo aproximou os pressupostos da ontologia construtivista realista dos estudos da estratégia como prática e ratificou o valor da contextualização (micro e macrossocial) para os estudos da organização. 


\section{REFERÊNCIAS BIBLIOGRÁFICAS}

BRAUN, V.; CLARKE, V. Using thematic analysis in psychology. Qualitative Research in Psychology, v. 3, n. 2, p. 77-101, 2006.

CRESWELL, John W.; CLARK, Vicki L. Plano. Designing and conducting mixed methods research. Sage publications, 2017.

DOMINGOS, Henderson MG; BAETA, Flávia Maria Coelho; BARBOSA, Márcia Adriana. A cachaça artesanal mineira: internacionalização e alianças estratégicas. Revista Gestão \& Tecnologia, v. 1, n. 1, 2002.

EISENHARDT, Kathleen M.; GRAEBNER, Melissa E. Theory building from cases: Opportunities and challenges. Academy of management journal, v. 50, n. 1, p. 25-32, 2007.

FLECK, Ludwik. Gênese e desenvolvimento de um fato científico: introdução à doutrina do estilo de pensamento e do coletivo de pensamento. Fabrefactum Editora, 2010.

GOLSORKHI, David; ROULEAU, Linda; SEIDEL, Daniel; VAARA, Eero. Introduction: What is Strategy as Practice? In: GOLSORKHI, David; ROULEAU, Linda; SEIDEL, Daniel; VAARA, Eero, (Orgs). Cambridge Handbook of Strategy as Practice, 2ed. Cambridge: Cambridge University Press, 2015.

GRAND, Simon; RÜEGG-STÜRM, Johannes; VON ARX, Widar. Constructivism epistemologies in Strategy as Practice research. In: GOLSORKHI, David; ROULEAU, Linda; SEIDEL, Daniel; VAARA, Eero, (Orgs). Cambridge Handbook of Strategy as Practice, 2ed. Cambridge: Cambridge University Press, 2015.

HYDLE, Katja Maria. Temporal and spatial dimensions of strategizing. Organization Studies, v. 36, n. 5, p. 643-663, 2015.

IBRAC. Instituto Brasileiro da Cachaça. 2020. Disponivel em: <http://www.ibraccachacas.org/>.
JARZABKOWSKI, Paula; BALOGUN, Julia; SEIDL, David. Strategizing: The challenges of a practice perspective. Human relations, v. 60, n. 1, p. 5-27, 2007.

KJELLBERG, Hans; HELGESSON, Claes-Fredrik. On the nature of markets and their practices. Marketing theory, v. 7, n. 2, p. 137-162, 2007.

NEUTZLING, D. M.;SANTOS, M.S.D.; BARCELLOS, M. D. D.; LAND, A. L. Value Creation from Internationalization of Sugar Cane by-products: a multi-stakeholder view of artisanal cachaça production. Revista Brasileira de Gestão de Negócios, v. 17, n. 55 , p. 890-910, 2015.

PAIVA, André Luiz, ANDRADE, Daniela, ANTONIALLI, Luis Marcelo, BRITO, Mozar José de. Strategic entrepreneurship: Observations from the practices of cachaça certification. RAM. Revista de Administração Mackenzie, v. 19, n. 2, 2018.

POTTER, Jonathan; WETHERELL, Margaret. Discourse and social psychology: Beyond attitudes and behaviour. Sage, 1987.

RECKWITZ, Andreas. Toward a theory of social practices: A development in culturalist theorizing. European journal of social theory, v. 5, n. 2, p. 243263, 2002.

RODRIGUES NETO, Antonio and FREITAS, Lucia Santana de. Análise do processo de adaptação estratégica de uma empresa produtora de cachaça à luz da Teoria Institucional e da Visão Baseada em Recursos. REAd. Rev. eletrôn. adm. (Porto Alegre) [online]. 2012, vol.18, n.1, pp.211-241.

SEIDL, David; WHITTINGTON, Richard. Enlarging the strategy-as-practice research agenda: Towards taller and flatter ontologies. Organization Studies, v. 35, n. 10, p. 1407-1421, 2014.

SHRIVASTAVA, Paul. Is strategic management ideological?. Journal of management, v. 12, n. 3, p. 363-377, 1986. 
SILVA, Floriana Rosa da. Na embriaguez da cachaça: produção, imaginário e marketing. Dissertação (Mestrado em História), Universidade Federal de Uberlândia, Uberlândia, 2009.

SORATTO, Alexandre Nixon; VARVAKIS, Gregorio; HORII, Jorge. A certificação agregando valor à cachaça do Brasil. Food Science and Technology, v. 27, n. 4, p. 681-687, 2007.

SOUZA, R. L. de. Cachaça, vinho, cerveja: da colônia ao século XX. Estudos Históricos, n. 33, p. 1-22, 2004 .

SPINK, Mary Jane; FREZZA, Rose Mary. Práticas discursivas e produção de sentidos: a perspectiva da psicologia social. In: SPINK, Mary Jane; FREZZA, Rose Mary. (Orgs.). Práticas discursivas e produção de sentidos no cotidiano: aproximações teóricas e metodológicas. 3a ed. São Paulo: Cortez, 1994.

VAARA, Eero; WHITTINGTON, Richard. Strategyas-practice: Taking social practices seriously. Academy of Management Annals, v. 6, n. 1, p. 285336, 2012.

VÁZQUEZ, Adolfo Sanchez. Filosofia da práxis. São Paulo: Expressão Popular, 2007.

VILLAR, Eduardo Guedes; WALTER, Suzana Anita. O Impacto dos Recursos de Cluster no Crescimento de Empresas: um Estudo de Caso em Pequenos Produtores de Cachaça de uma Região de Santa Catarina. EGEPE, Goiânia, 2014.

WHITTINGTON, Richard. Completing the practice turn in strategy research. Organization studies, v. 27, n. 5, p. 613-634, 2006. 